\title{
TU/e EmonOWEN

\section{Migration behaviour of micelle counterions in micellar electrokinetic chromatography: Influence on micelle mobility, efficiency and selectivity}

Citation for published version (APA):

Muijselaar, W. G. H. M., Claessens, H. A., \& Cramers, C. A. M. G. (1997). Migration behaviour of micelle counterions in micellar electrokinetic chromatography: Influence on micelle mobility, efficiency and selectivity. Journal of Chromatography, A, 764(1), 127-133. https://doi.org/10.1016/S0021-9673(96)00893-X

DOI:

10.1016/S0021-9673(96)00893-X

Document status and date:

Published: 01/01/1997

Document Version:

Publisher's PDF, also known as Version of Record (includes final page, issue and volume numbers)

\section{Please check the document version of this publication:}

- A submitted manuscript is the version of the article upon submission and before peer-review. There can be important differences between the submitted version and the official published version of record. People interested in the research are advised to contact the author for the final version of the publication, or visit the $\mathrm{DOI}$ to the publisher's website.

- The final author version and the galley proof are versions of the publication after peer review.

- The final published version features the final layout of the paper including the volume, issue and page numbers.

Link to publication

\footnotetext{
General rights

- You may freely distribute the URL identifying the publication in the public portal. follow below link for the End User Agreement:

www.tue.nl/taverne

Take down policy

If you believe that this document breaches copyright please contact us at:

openaccess@tue.nl

providing details and we will investigate your claim.
}

Copyright and moral rights for the publications made accessible in the public portal are retained by the authors and/or other copyright owners and it is a condition of accessing publications that users recognise and abide by the legal requirements associated with these rights.

- Users may download and print one copy of any publication from the public portal for the purpose of private study or research.

- You may not further distribute the material or use it for any profit-making activity or commercial gain

If the publication is distributed under the terms of Article $25 \mathrm{fa}$ of the Dutch Copyright Act, indicated by the "Taverne" license above, please 


\title{
Migration behaviour of micelle counterions in micellar electrokinetic chromatography: influence on micelle mobility, efficiency and selectivity
}

\author{
Pim G. Muijselaar*, Henk A. Claessens, Carel A. Cramers \\ Laboratory of Instrumental Analysis, Eindhoven University of Technology, P.O. Box 513, 5600 MB Eindhoven, The Netherlands
}

Received 24 July 1996; revised 16 October 1996; accepted 16 October 1996

\begin{abstract}
The migration behaviour of micelle counterions in micellar electrokinetic chromatography (MEKC) is treated theoretically. It is demonstrated that, due to a high degree of counterion binding, micelle counterions in commonly used surfactant systems possess negative transport numbers under MEKC conditions. This phenomenon is illustrated for a sodium dodecyl sulphate micellar system in which sodium ions possess a negative effective mobility. In addition to that, the influence of sodium and tris(hydroxymethyl)aminomethane as dodecyl sulphate counterions on the effective mobility of micelles, efficiency and selectivity in MEKC analyses is evaluated.
\end{abstract}

Keywords: Micelle counterions; Buffer composition; Sodium; Tris(hydroxymethyl)aminomethane; Dodecyl sulfate

\section{Introduction}

Micellar electrokinetic chromatography (MEKC) is a highly efficient separation technique, especially suitable for the analyses of neutral species $[1,2]$. The separation mechanism is based on the distribution of sample compounds between a pseudo-stationary micellar phase and an aqueous mobile phase. These two phases move with different velocities according to electrokinetic phenomena, thus combining both chromatographic and electrophoretic principles. A main advantage of MEKC is the possibility to change the composition of the electrolyte system in order to optimize selectivity and efficiency. Besides the hydrophilic moieties of the micellar phase, also

\footnotetext{
${ }^{*}$ Corresponding author. Present address: Faculty of Science, Himeji Institute of Technology, Kamigori, Hyogo 678-12, Japan.
}

the chemical nature of the counterions may affect solute-micelle interactions. Several authors paid attention to the influence of inorganic and organic counterions of dodecyl sulphate micelles in MEKC [3-7]. Cohen et al. [3] reported an improved resolution for oligonucleotides due to complexation with divalent micelle counterions. Nishi et al. [4] and Nielsen and Foley [5] described the effect of tetraalkylammonium salts in an SDS micellar system on selectivity and resolution. Also, the high degree of counterion binding has been applied for the separation of anionic species applying MEKC with cationic surfactant systems $[8,9]$.

Resolution in MEKC is influenced by the efficiency, selectivity, solute retention, and elution window [2]. All these terms depend on the structure and microenvironment of the pseudo-stationary micellar phase. The chemical nature of counterions 
may have a pronounced effect on micellar structure $[10,11]$ and consequently on the resolution in MEKC experiments. Therefore a good understanding of the migration behaviour of micelle counterions and their influence on the separation process is important, both from an electrophoretic and a chromatographic point of view.

In this paper we describe the migration behaviour of sodium counterions during MEKC experiments with a sodium dodecyl sulphate micellar system. In addition, the influence of sodium and tris(hydroxymethyl)aminomethane counterions on micelle mobility, separation efficiency and selectivity is discussed.

\section{Theory}

In an aqueous solution of an ionic surfactant three constituents can be distinguished, viz. the solvent water, an amphiphilic ion and a hydrophilic counterion. Above the critical micelle concentration (CMC) micelles will be formed which can be described by the following equilibrium [10]:

$m \mathrm{M}+n \mathrm{~A} \rightleftarrows \mathrm{M}_{m} \mathrm{~A}_{n}$

where $\mathrm{M}$ denotes the counterions, $\mathrm{A}$ the amphiphilic ions and MA the micelles, respectively. Hence $n$ is the aggregation number and $m$ is the number of counterions bound to the micelle. The degree of counterion binding, $\theta$, is defined as the ratio of counterions and amphiphilic ions in a micelle $(\mathrm{m} / \mathrm{n})$. For a large number of surfactant systems, $\theta$ lies in the range $0.5-0.8$. The degree of dissociation of the micelles, $\alpha$, equals $1-\theta$.

Mysels and Dulin [12] described a model for an anionic surfactant where three different ionic species will be present in solution, viz. $\mathrm{M}^{+}$ions, $\mathrm{A}^{-}$ions and micelles composed of $n \mathrm{~A}^{-}$and $\theta n \mathrm{M}^{+}$ions with the empirical formula $\mathrm{M}_{\theta} \mathrm{A}$. If these three species are denoted by numerical subscripts 1,2 and 3 respectively, the following material balances can be derived for the concentration of the surfactant, $C_{\mathrm{SF}}$, and the different species:

$C_{\mathrm{SF}}=C_{\mathrm{M}}=C_{\mathrm{A}}=C_{2}+C_{3}=C_{1}+\theta C_{3}$

where $C_{\mathrm{M}}$ and $C_{\mathrm{A}}$ are the total concentrations of counterions and amphiphilic ions, respectively. The effective mobility of the amphiphilic ions, $m_{\text {eff. A }}$, is the weighted average of the mobility of the free $\mathrm{A}^{-}$ ions at the CMC, $m_{2}$, and the effective mobility of the micelles, $m_{3}$, according to:

$m_{\mathrm{eff} . \mathrm{A}}=\frac{C_{2}}{C_{\mathrm{SF}}} m_{2}+\frac{C_{3}}{C_{\mathrm{SF}}} m_{3}$

where $C_{2}$ is the $\mathrm{CMC}$ and $C_{3}=C_{\mathrm{SF}}-C_{2}$. The effective mobility of the counterions, $m_{\text {eff.M }}$, is the weighted average of the mobility of the free $\mathrm{M}^{+}$ions at the CMC, $m_{1}$, and the effective mobility of the micelles, $m_{3}$, according to:

$m_{\text {eff. } . \mathrm{M}}=\frac{C_{1}}{C_{\mathrm{SF}}} m_{1}+\frac{\theta C_{3}}{C_{\mathrm{SF}}} m_{3}$

where $C_{1}=C_{\mathrm{SF}}-\theta C_{3}$. The mobility of the free $\mathrm{A}^{-}$ ions and $\mathrm{M}^{+}$ions at the $\mathrm{CMC}, m_{2}$ and $m_{1}$, can be calculated from their ionic mobilities at infinite dilution, $m_{\mathrm{A}^{-}}^{0}$ and $m_{\mathrm{M}^{+}}^{0}$, applying the DebyeHückel-Onsager theory for the correction of relaxation and retardation effects [13]. An approximation for the degree of dissociation of the micelles, $\alpha$, can be obtained from the differential conductivity, $\partial \kappa /$ $\partial C_{\mathrm{SF}}$, which above the $\mathrm{CMC}$ can be described by [14]:

$\frac{\partial \kappa}{\partial C_{\mathrm{SF}}}=\alpha\left(\lambda_{\mathrm{M}^{+}}+F m_{3}\right)$

where $\lambda_{\mathrm{M}^{+}}$is the molar ionic conductivity of the counterions at the CMC and $F$ is the Faraday constant. From literature data for the conductivity of sodium dodecyl sulphate (SDS) [15] and assuming an effective mobility of $-45.33 \cdot 10^{-5} \mathrm{~cm}^{2} / \mathrm{V} \mathrm{s}$ for SDS micelles, a value of 0.26 is calculated for $\alpha$. This means that about $74 \%$ of the counterions are bound to the micelles in an SDS micellar system. Here it should be noted that the degree of dissociation is actually not constant but increases slightly with increasing surfactant concentration [12]. In Fig. $1 m_{\text {eff.A }}$ and $m_{\text {eff, }}$ are shown as a function of surfactant concentration for a specific anionic micellar system. The reduction of viscous drag on micellization, i.e., a micelle formed by $n$ surfactant molecules experiences less viscous drag than the total viscous drag experienced by $n$ individual surfactant molecules, causes an increase in effective mobility of 


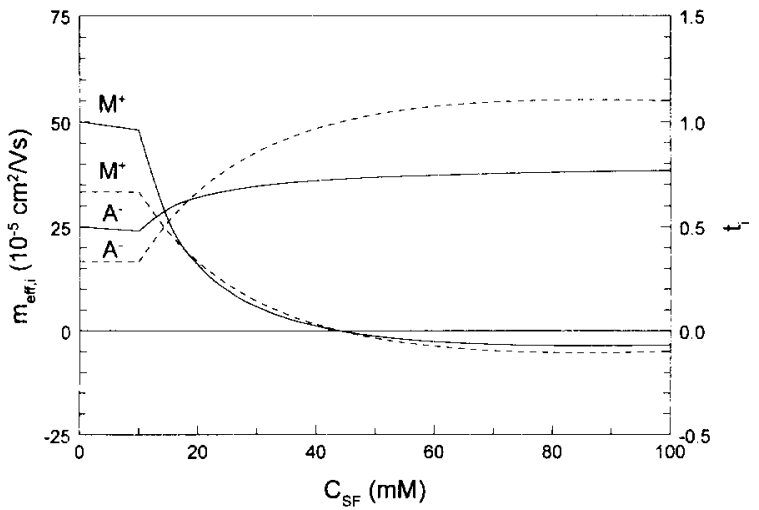

Fig. 1. Effective mobility (drawn lines, left hand ordinate) and transport number (dotted lines, right hand ordinate) for amphiphilic ions, $-m_{\mathrm{cit} . \mathrm{A}}$ and $t_{\mathrm{A}}$, and counterions, $m_{\mathrm{ctri.}}$ and $t_{\mathrm{M}}$, versus surfactant concentration, $C_{\mathrm{SF}}$. Model values: $\mathrm{CMC}=10$ $\mathrm{m} M, m_{\mathrm{A}^{-}}^{\prime \prime}=-25 \cdot 10^{-5} \mathrm{~cm}^{2} / \mathrm{V} \mathrm{s}, m_{\mathrm{M}^{+}}^{\prime \prime}=+50 \cdot 10^{-5} \mathrm{~cm}^{2} / \mathrm{V} \mathrm{s}, m_{3}=$ $-40 \cdot 10^{-5} \mathrm{~cm}^{2} / \mathrm{V} \mathrm{s}, \alpha=0.25+0.001 C_{\mathrm{SF}}$.

amphiphilic ions above the CMC. Due to the binding of counterions to micelles their effective mobility decreases above the CMC. The transport of bound counterions predominates over the migration of free counterions, due to a high degree of counterion binding and a high absolute value for the effective mobility of micelles. This results in a negative effective mobility for $\mathrm{M}^{+}$which means that the net migration of the positive counterions is towards the anode. In Fig. 1 also the transport numbers for $\mathrm{A}$ and $M$ are shown. The transport number of an ionic species in solution is the fraction of the current carried by that species across a reference plane when an electric current is passed through the solution [16]. Thus, the transport number, $t_{i}$, is expressed by:

$t_{i}=\frac{i_{i}}{\sum_{j} i_{j}}=\frac{C_{i} z_{i} m_{i}}{\sum_{j} C_{j} z_{j} m_{j}}$

where $i_{i}=$ current carried by the ion $i, \Sigma_{j} i_{j}=$ current carried by all the ions in solution, $C_{i}=$ concentration of ion $i, z_{i}=$ charge number of ion $i, m_{i}=$ effective mobility of ion $i$.

The sum of transport numbers of all ionic species present in a solution equals unity:

$$
\sum_{i} t_{i}=1
$$

In the case of a single anionic surfactant solution with $C_{\mathrm{M}}=C_{\mathrm{A}}$ Eq. (6) reduces to:

$t_{i}=\frac{i_{i}}{\sum_{j} i_{j}}=\frac{z_{i} m_{i}}{\sum_{j} z_{j} m_{j}}$

Due to micellization $t_{\mathrm{A}}$ exceeds unity at higher surfactant concentrations, whereas $t_{\mathrm{M}}$ becomes negative due to counterion binding.

\section{Experimental}

\subsection{Chemicals}

Sodium dodecyl sulphate (SDS), was obtained from Aldrich (Steinheim, Germany). Tris(hydroxymethyl)aminomethane (Tris), was obtained from Merck (Darmstadt, Germany). The Tris salt of dodecyl sulphate (TDS) was obtained from Sigma (St. Louis, MO, USA). All other chemicals were of analytical-reagent grade.

\subsection{Instrumentation and separation conditions}

All experiments were carried out on a BioFocus 3000 Capillary Electrophoresis System (BioRad, Hercules, CA, USA) at a constant voltage of $20 \mathrm{kV}$. $50 \mu \mathrm{m}$ I.D. fused-silica capillaries (Polymicro Technologies, Phoenix, AZ, USA) were used, total length $70.0 \mathrm{~cm}$, distance between injection and detection $65.4 \mathrm{~cm}$, or total length $50.0 \mathrm{~cm}$, distance between injection and detection $45.4 \mathrm{~cm}$. The temperature was kept constant at $25^{\circ} \mathrm{C}$ and the wavelength of the detector was set at $200 \mathrm{~nm}$. Samples were introduced by pressure injection with an injection constant of 1 p.s.i. s $(1$ p.s.i. $=6894.76 \mathrm{~Pa})$, unless otherwise noted.

\section{Results and discussion}

\subsection{Migration behaviour of micelle counterions}

In order to investigate the migration behaviour of sodium ions in an SDS micellar system, experiments were carried out with an electrolyte system compris- 
ing $20 \mathrm{mM}$ imidazole adjusted to $\mathrm{pH} 8.5$ by addition of boric acid, containing different concentrations SDS. A sample solution of SDS in deionized water was injected, containing the same concentration SDS as the electrolyte system. For the electrolyte system without SDS, a sample solution of $1 \mathrm{~m} M$ SDS was applied. Due to field amplified sample stacking a small increase in the sodium concentration is obtained in this sample plug, which can be visualized applying indirect UV detection. Besides the sodium peak and the electroosmotic flow (EOF) dip, system peaks were also observed as described by Beckers [17]. In Fig. 2 all electrokinetic chromatograms are shown. Without SDS sodium migrates in the downstream mode [18] towards the cathode and is detected before the EOF. On increasing the SDS concentration the effective mobility decreases and becomes negative above ca. $10 \mathrm{~m} M$ SDS. In this situation sodium migrates in the upstream mode towards the anode and is detected after the EOF. Here it should be emphasized that it is difficult to distinguish between the two negative peaks after the EOF at higher SDS concentrations and to determine which peak should be attributed to sodium. Since the effect of field amplified sample stacking will de-

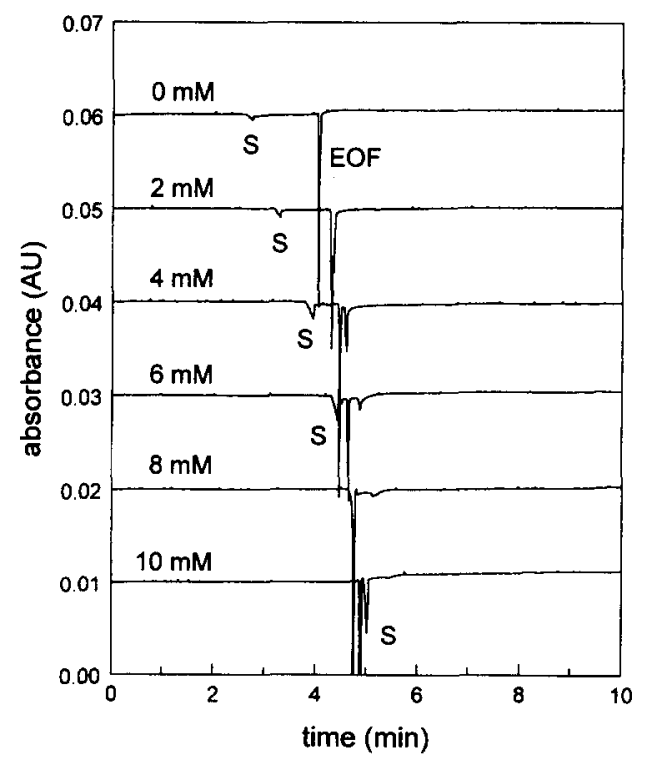

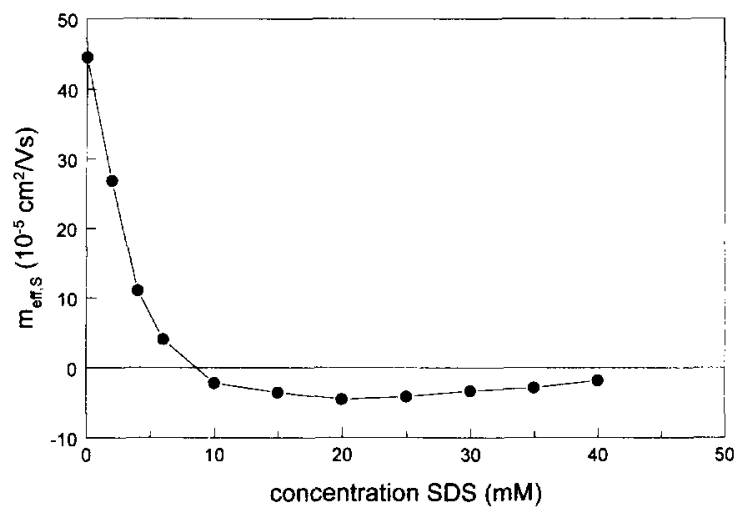

Fig. 3. Calculated effective mobility for sodium, $m_{\mathrm{efr}, \mathrm{s}}$, versus concentration SDS in an electrolyte system of $20 \mathrm{mM}$ imidazole adjusted to $\mathrm{pH} 8.5$ by addition of boric acid.

crease at higher SDS concentrations, we assume that the first peak represents sodium, as this peak decreases at higher SDS concentrations. In Fig. 3 all calculated effective mobilities are shown. These results illustrate that under normal MEKC conditions with an SDS micellar system the micelle counterions have a negative effective mobility and consequently a negative transport number.

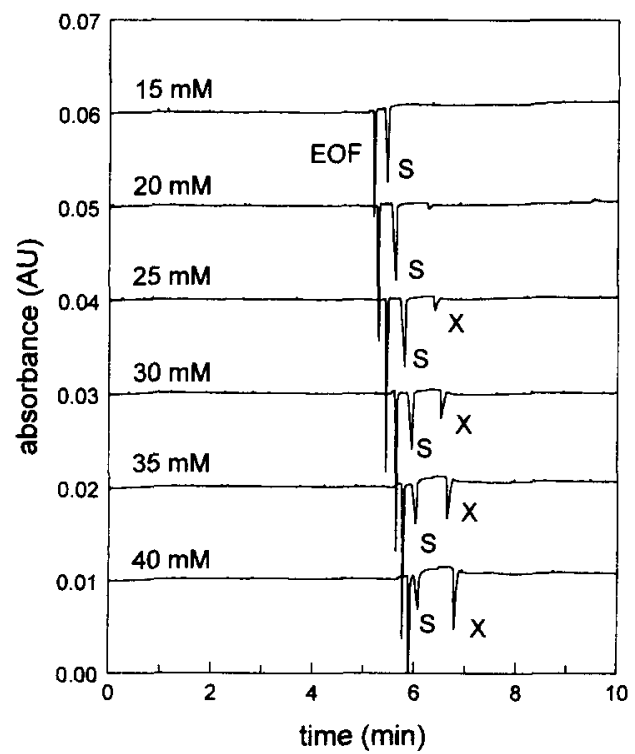

Fig. 2. Electrokinetic chromatograms of sodium, S, and a system peak, $\mathrm{X}$, in an electrolyte system of $20 \mathrm{~m} M$ imidazole adjusted to $\mathrm{pH} 8.5$ by addition of boric acid, containing different SDS concentrations $(\mathrm{m} M)$. Sample solution, SDS in deionized water at the same concentration as the electrolyte system. Capillary length, $70.0 \mathrm{~cm}$. For further explanation, see text. 


\subsection{Migration behaviour of micelles}

The size and valency of counterions associated with an ionic amphiphile may have a pronounced effect on micellar properties such as aggregation number and $\mathrm{CMC}$. Also, the degree of ionization may be influenced by the effective hydrated radius of the counterion. In addition to that, the ionic strength of the applied background electrolyte may influence micellar size and shape $[10,11]$. Moreover, ionic constituents of the buffer may be bound to the micelles as counterions. For these reasons the effective mobility of micelles will not only be dependent on the applied surfactant system with a specific type of counterions, but also on the chemical nature of the background electrolyte.

In order to investigate the influence of counterions on the migration behaviour of micelles, effective mobilities of dodecyl sulphate (DS) micelles were measured with sodium and Tris as counterions, respectively. The migration time of the micelles was calculated by an iteration procedure applying the migration data of a homologous series of alkylbenzenes $[19,20]$. Special attention was paid to the composition of the background electrolytes so that the cation was identical to the DS counterion. As can be seen from the results, listed in Table 1, higher effective mobilities for DS micelles are obtained with sodium counterions (SDS) than with Tris counterions (TSD). Due to a larger effective hydrated radius of Tris compared to sodium, the degree of dissociation and consequently the net charge will be higher for TDS micelles, causing an increase in effective mobility. However, this effect is counteracted by a larger effective size for TDS micelles, causing a decrease in effective mobility. Obviously the larger micelle size predominates the higher degree of dissociation, resulting in a lower effective mobility of TDS micelles.
Table 2

Theoretical plate numbers, $N \cdot 10^{-5}$, and methylene selectivity, $\log$ $\alpha_{\mathrm{CH}_{2}}$, with standard deviations (in parentheses) for a homologous series of alkylbenzenes in SDS and TDS surfactant systems, capillary length $=50.0 \mathrm{~cm}$

\begin{tabular}{lll}
\hline Compound & $50 \mathrm{~m} M$ SDS & $50 \mathrm{~m} M$ TDS \\
\hline Benzene & 1.79 & 1.87 \\
Toluene & 1.72 & 2.22 \\
Ethylbenzene & 1.44 & 2.07 \\
Propylbenzene & 0.91 & 2.39 \\
Butylbenzene & 1.04 & 2.38 \\
$\log \alpha_{\mathrm{CH}_{2}}$ & $0.418(0.005)$ & $0.410(0.005)$ \\
\hline
\end{tabular}

The results in Table 1 also illustrate that on applying an electrolyte system containing Tris as buffering cationic species and SDS as micelle forming agent, the effective mobility of DS micelles is mainly determined by the presence of the Tris cations. These results demonstrate that Tris cations present in the background electrolyte are bound as counterions to DS micelles for a considerable extent in this electrolyte system.

\subsection{Efficiency}

To study the influence of micelle counterions on efficiency in MEKC, experiments were carried out with a homologous series of alkylbenzenes, applying SDS and TDS as micellar system, respectively. As can be seen from the theoretical plate numbers, listed in Table 2, higher separation efficiencies are obtained with TDS for all compounds. Due to a smaller hydrated radius, sodium counterions are able to approach the charged sulphate groups of DS micelles more closely than Tris counterions. As a consequence, the electrical repulsion of aggregated DS molecules will be reduced more effectively, allowing the sulphate groups to approach closer to each other

Table 1

Effective mobility of DS micelles, $m_{\mathrm{MC}}\left(10^{-5} \mathrm{~cm}^{2} / \mathrm{V} s\right)$, with standard deviations (in parentheses) with sodium and Tris counterions in different electrolyte systems $(n=5)$

\begin{tabular}{|c|c|c|c|c|}
\hline $\begin{array}{l}\text { Cation } \\
(20 \mathrm{~m} M)\end{array}$ & Buffering counter species & $\mathrm{pH}$ & $\begin{array}{l}\text { Surfactant system } \\
(50 \mathrm{~m} M)\end{array}$ & $m_{\mathrm{MC}}$ \\
\hline $\mathrm{NaOH}$ & $o$-Phosphoric acid & 7.0 & SDS & $-45.33(0.50)$ \\
\hline Tris & $o$-Phosphoric acid & 7.0 & TDS & $-38.44(0.11)$ \\
\hline Tris & $o$-Phosphoric acid & 7.0 & SDS & $-39.16(0.10)$ \\
\hline
\end{tabular}


$[10,11]$. Therefore, TDS micelles will possess a less rigid structure of the polar head groups and a less compact double layer than SDS micelles, resulting in improved sorption-desorption kinetics and higher separation efficiencies. This effect will be more pronounced for hydrophobic compounds, which explains the larger differences in theoretical plate numbers obtained for higher homologues.

\subsection{Selectivity}

\subsubsection{Hydrophobic selectivity}

Hydrophobic or methylene selectivity provides information about differences in polarity between the aqueous mobile phase and the pseudo-stationary micellar phase. The hydrophobic selectivity, log $\alpha_{\mathrm{CH}_{2}}$, of a micellar system can be calculated from the migration data of a homologous series with an increasing number of methylene groups, according to [21]:

$\log k=\left(\log \alpha_{\mathrm{CH}_{2}}\right) z+b$

where $k$ is the retention factor, $z$ is the number of carbon atoms in the homologues and $b$ is a constant which depends amongst others on the phase ratio. A lower value of $\log \alpha_{\mathrm{CH}_{2}}$ indicates a more polar microenvironment in the micellar phase. In Table 2 $\log \alpha_{\mathrm{CH}_{2}}$ is listed for the homologous series of alkylbenzenes in an SDS and a TDS micellar system, respectively. As can be seen from these results, only a small difference is observed between the hydrophobic selectivity for these two pseudo-stationary phases. TDS micelles provide a slightly more polar microenvironment for the alkylbenzenes. The less rigid structure of the polar head groups allows for an increase of water penetration into the micellar surface and a higher extent of hydration of the sulphate groups. However, since nonpolar compounds are solubilized in the hydrophobic micelle interior [22], only a minor influence is observed for the methylene selectivity of DS micelles applying alkylbenzene homologues.

\subsubsection{Functional group selectivity}

Recently it was demonstrated that counterions of dodecyl sulphate micelles do not have a significant influence on functional group selectivity in MEKC

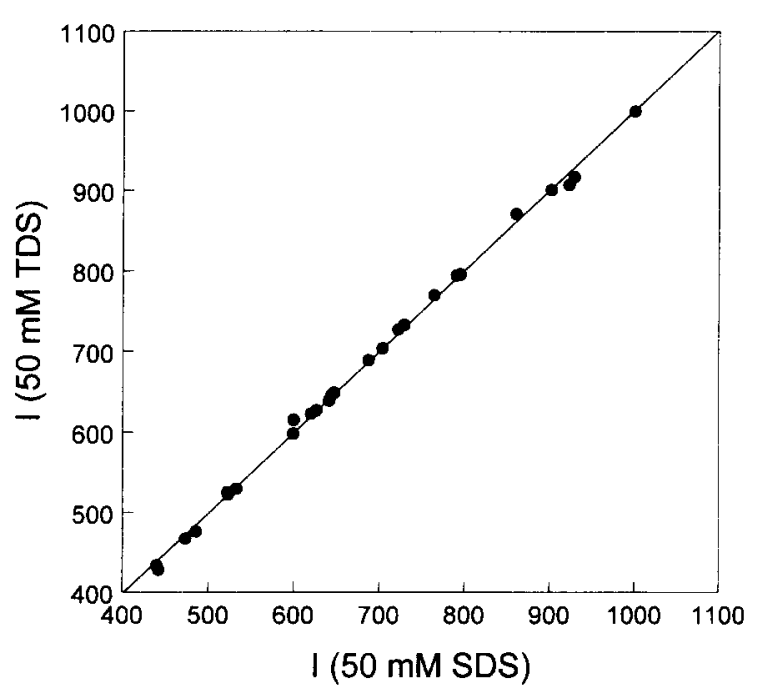

Fig. 4. Comparison of retention indexes for 28 sample compounds possessing different functionalities, obtained in electrolyte systems of $20 \mathrm{mM} \mathrm{NaOH}$ adjusted to $\mathrm{pH} 7.0$ by addition of $o$-phosphoric acid, containing $50 \mathrm{~m} M$ SDS and $20 \mathrm{mM}$ Tris adjusted to $\mathrm{pH} 7.0$ by addition of $o$-phosphoric acid, containing $50 \mathrm{mM}$ TDS, respectively. See [23] for the names of the sample compounds. Retention index standards, alkylbenzenes.

analysis [7,23]. This is illustrated in Fig. 4 for a group of 28 sample compounds possessing different functionalities and hydrophobicity. Retention indexes were determined for these compounds in electrolyte systems containing SDS and TDS as micellar phases, respectively, applying a homologous series of alkylbenzenes as retention index standards [19]. Fig. 4 clearly illustrates that for these sample compounds with various functional groups the influence of micelle counterions on selectivity is of minor importance. The influence of the chemical nature of the polar head group of the applied surfactant on selectivity is of much greater importance $[19,23]$.

\section{Conclusions}

Due to a high degree of counterion binding to micelles, negative transport numbers are obtained for counterions in MEKC experiments, i.e., the net migration of sodium is towards the anode in an SDS micellar system.

The mobility of micelles is influenced by the effective hydrated radius of counterions and the 
degree of counterion binding. Consequently, lower effective mobilities were obtained for TDS micelles than for SDS micelles. It was demonstrated that the effective mobility of DS micelles decreases if a background electrolyte is applied containing Tris as buffering cationic species due to binding of Tris to DS micelles as counterions.

Higher separation efficiencies were obtained for TDS than for SDS, due to a less rigid structure of the micelle surface and a less compact double layer. The influence of micelle counterions on hydrophobic selectivity and functional group selectivity was shown to be of minor importance.

\section{Acknowledgments}

The authors express their gratitude to the Netherlands Foundation for Chemical Research (SON) for financial support of this investigation and to Dr. $J$. Beckers and Dr. J. Reijenga for stimulating discussions.

\section{References}

[1] S. Terabe, K. Otsuka, K. Ichikawa, A. Tsuchiya and T. Ando, Anal. Chem., 56 (1984) 113.

[2] S. Terabe, K. Otsuka and T. Ando, Anal. Chem., 57 (1985) 834.

[3] A.S. Cohen, S. Terabe, J.A. Smith and B.L. Karger, Anal. Chem., 59 (1987) 1021.
[4] H. Nishi, N. Tsumagari and S. Terabe, Anal. Chem., 61 (1989) 2434.

[5] K.R. Nielsen and J.P. Foley, J. Microcol. Sep., 6 (1994) 139.

[6] K.R. Nielsen and J.P. Foley, J. Microcol. Sep., 5 (1993) 347.

[7] E.S. Ahuja and J.P. Foley, Anal. Chem., 67 (1995) 2315.

[8] T. Kaneta, S. Tanaka, M. Taga and H. Yoshida, Anal. Chem., 64 (1992) 798

[9] M. Martínez and M. Aguilar, J. Chromatogr. A, 676 (1994) 443.

[10] B. Lindman and H. Wennerström, Topics in Current Chemistry, Vol. 87, Springer Verlag, Berlin, 1980.

[11] D. Attwood and A.T. Florence, Surfactant Systems, Chapman and Hall, London, 1983.

[12] K.J. Mysels and C.I. Dulin, J. Colloid Sci., 10 (1955) 461.

[13] H. Falkenhagen, Elektrolyte, Hirzel, Leipzig, 1932.

[14] P. Mukerjee, K. Mysels and P. Kapauan, J. Phys. Chem., 71 (1967) 4166.

[15] O.R. Howell and H.G.B. Robinson, Proc. R. Soc. London, 155 (1936) 386.

[16] A.L. Horvath, Handbook of Aqueous Electrolyte Solutions, Ellis Horwood, Chichester, 1985, p. 239.

[17] J.L. Beckers, J. Chromatogr. A, 662 (1994) 153.

[18] F.M. Everaerts, A.A.A.M. Van de Goor, Th P.E.M. Verheggen and J.L. Beckers, J. High Resolut. Chromatogr., 12 (1989) 28.

[19] P.G. Muijselaar, H.A. Claessens and C.A. Cramers, Anal. Chem., 66 (1994) 635.

[20] M.M. Bushey and J.W. Jorgenson, Anal. Chem., 61 (1989) 491.

[21] P. Jandera, J. Chromatogr., 314 (1984) 13.

[22] P.H. Elworthy, A.T. Florence and C.B. Macfarlane, Solubilization by Surface-Active Agents, Chapman and Hall, London, 1968, p. 67.

[23] P.G. Muijselaar, H.A. Claessens and C.A. Cramers, Anal. Chem., submitted for publication. 